\title{
ESTUDOS COMPARADOS: SUA EPISTEMOLOGIA E SUA HISTORICIDADE
}

\author{
COMPARED STUDIES: EPISTEMOLOGY AND HISTORICITY
}

\author{
Maria Ciavatta ${ }^{1}$
}

Resumo A comparação parte da analogia que é o processo de perceber as diferenças e semelhanças na relação com o outro, pessoas e objetos. A questão do outro e do reconhecimento da alteridade é a base do conhecimento da identidade de si mesmo e da distinção em relação aos demais seres. Assim como as ciências têm uma gênese e um desenvolvimento ao longo da história da humanidade, as questões epistemológicas também possuem uma historicidade. Ao refletir sobre a verdade dos estudos comparados, sobre sua epistemologia, vemos que eles se fazem compreensíveis e convincentes na medida em que a sociologia, a história, a antropologia, a política, a educação etc. são remetidas à história de sua elaboração. Nelas estão presentes os sujeitos sociais que as produziram e as ideologias que permearam suas ideias sobre a verdade científica. Neste texto, após algumas questões preliminares que o tratamento do tema requer, a saber, conhecimento e verdade, história e historicidade e o sentido da comparação, apresento alguns autores de referência que se ocuparam do tema e, a seguir, alguns estudos comparativos que desenvolvi em elaborações anteriores sobre a questão.

Palavras-chave estudos comparados; educação; epistemologia; educação profissional.
Abstract The comparison is based on the analogy that is the process of perceiving the differences and similarities in the relationship with the other, people and objects. The issue about the other and the recognition of alterity is the basis of the knowledge of the very own identity and of the distinction in regards to the other beings. Just as sciences have a genesis and a development along the mankind history, the epistemological issues also bear a historicity. When reflecting about the truth of compared studies, about their epistemology, we see they are understandable and convincing as the sociology, the history, the anthropology, the politics, the education etc. refer to the history of their creation. There in the social subjects who produced them are present, as well as the ideologies that pervaded their ideas regarding the scientific truth. In this text, after some preliminary questions required by the handling of the issue, which are, knowledge and truth, history and historicity and the meaning of comparison, I present some reference authors who dealt with this theme and, as follows, some comparative studies I developed in previous creations regarding the matter.

Keywords compared studies; education; epistemology; professional education. 


\begin{abstract}
Quiero hablar del descubrimiento que el yo hace del outro. El tema el inmenso. Apenas lo formula uno en su generalidad, ve que se subdivide en categorias y en direcciones múltiples, infinitas. Uno pude descubrir a los otros en uno mismo, darse cuenta de que no somos una substancia homogénea, y radicalmente estraña a todo que nos es uno mismo: yo es otro (Todorov, 1987).
\end{abstract}

\title{
Introdução
}

A comparação é uma constante na produção intelectual, não apenas nos trabalhos acadêmicos, mas também nos aprendizados da vida cotidiana. Como haveríamos de nos considerar homens ou mulheres sem um exercício inicial de conhecer as características particulares das pessoas do sexo masculino e aquelas do sexo feminino e, por um processo de analogia entre uns e outros, encontrar as semelhanças e as diferenças e chamar a uns de homens e a outros de mulheres? E assim, indefinidamente, através de analogias, a humanidade e, ao longo dos tempos, cada ser humano que nasce e cresce vai distinguindo umas coisas das outras e se dando conta de como é e como se chama cada ser, objeto, fenômeno ou acontecimento que o rodeia.

Neste fato primordial, coloca-se a questão da linguagem, a denominação comum para um objeto entre todos os sujeitos que partilham determinada língua ou suas variações linguísticas. A relação íntima entre pensamento e linguagem é objeto de estudos de linguistas e especialistas e não é objeto deste artigo. Estas considerações são apenas ponto de partida para uma reflexão sobre o que é comparar e suas exigências epistemológicas.

A questão do outro e do reconhecimento da alteridade como base do conhecimento da identidade de si mesmo e da distinção dos outros seres humanos e de todo e qualquer objeto é o tema de um livro seminal de Tzvetan Todorov (1987) sobre o sentido da conquista da América e da colonização dos países do hemisfério sul pelos europeus, espanhóis e portugueses. A 'verdade' dos relatos que acompanham o descobrimento é tratada na historicidade das relações e da comparação que se estabelecem entre os conquistadores e os povos indígenas habitantes da região.

É possível afirmar que a epistemologia é uma 'meta-ciência', porque ela se ocupa da 'verdade' sobre o que é a 'verdade' ou como se produz a verdade do conhecimento dito verdadeiro nas ciências físicas, matemáticas, humanas e/ou sociais. Assim como as ciências têm uma gênese e um desenvolvimento ao longo da história da humanidade, a epistemologia também possui uma historicidade. Mas o apelo à epistemologia neste texto não é para 
tecer considerações sobre o conceito geral de epistemologia. Disto se ocupam outros especialistas, a exemplo de Japiassu (1977), Bachelard (1977) e outros.

Ao refletir sobre a verdade dos estudos comparados, sobre sua epistemologia, vemos que os estudos comparados se fazem compreensíveis e convincentes na medida em que a sociologia, a história, a antropologia, a política, a educação etc., para ficar só nas ciências humanas e/ou sociais, são remetidas à história de sua elaboração. Nelas estão presentes os sujeitos sociais que as produziram e as ideologias que permearam suas ideias sobre a verdade científica.

Antes de trazer algumas ideias sobre os estudos comparados nas ciências sociais e, de modo especial, em educação, vamos nos deter brevemente sobre três questões preliminares que o tratamento do tema requer: conhecimento e verdade; história e historicidade; e o sentido da comparação. A seguir trarei alguns autores que se ocupam dos estudos comparados e alguns estudos comparativos que desenvolvi em elaborações anteriores sobre o tema (Ciavatta Franco, 1992a, 1998, 2000a; Ciavatta, 2006).

\section{Questões preliminares: conhecimento, verdade e comparação}

A questão do conhecimento tem uma história milenar na filosofia. Ela diz respeito à forma e ao sentido da aproximação do ser humano de toda e qualquer parcela do real, daquilo sobre o qual ele pode fazer uma representação para si mesmo, levando-o à sua consciência, reconhecendo-o, nomeando-o e partilhando de uma denominação comum. Em outros termos, busca-se compreender como um objeto externo ou interno se apresenta à inteligência e à sensibilidade dos indivíduos.

Esse fato ou ato de conhecer implica uma relação entre o sujeito que conhece e o objeto, a ideia, o sentimento, a emoção etc. conhecidos. O que coloca dois novos problemas epistemológicos: o da verdade desse conhecimento e de seu caráter objetivo ou subjetivo.

Analisando a questão da verdade na história, Virgínia Fontes (2001, p. 107-109) pergunta: “existe verdade? Existe uma única verdade? A história é um relato (ou narrativa) verdadeiro?" A autora rejeita, logo de partida, a ideia de verdade absoluta, a verdade dogmática que pertence ao domínio da religião. Também rejeita a verdade relativa que culmina na inexistência de qualquer verdade, supondo-se que tudo é uma questão de crença ou de opinião. Outros aspectos importantes da concepção de verdade é seu atravessamento pelas ideologias, que justificam os interesses de classe, e pela política, pelo poder que se exerce na vida social.

A questão da objetividade e da subjetividade do conhecimento fica mais facilmente compreensível quando refletimos sobre o que é a arte ou o conhecimento 
expresso pelo artista. A questão da natureza da representação artística é uma discussão clássica da filosofia e pode ser resumida na questão do realismo estético. A obra de arte seria uma representação fiel, cópia exata, 'verdadeira' da realidade exterior ou seria uma interpretação subjetiva que o artista faz do objeto representado?

No primeiro caso, existiria uma realidade exterior autônoma, independente do conhecimento que se pode ter sobre ela. $\mathrm{O}$ conhecimento verdadeiro seria a coincidência ou correspondência entre o que pensamos ou representamos e a realidade. Na arte, seria a reprodução mais fiel possível do objeto representado. No segundo caso, a representação seria uma criação do sujeito e, no limite, ela perderia todo contato com a realidade, podendo ser apenas um fato de consciência, negando, implicitamente, a exterioridade do objeto representado. O que contraria a evidência da materialidade da criação artística.

Lukács é um dos autores que de forma mais original e objetiva enfrenta teoricamente a questão. Na sua Introdução a uma estética marxista (Lukács, 1992, p. 190), diz: "Esse problema da humanidade da arte é indissoluvelmente ligado ao da sua objetividade e subjetividade." Seu raciocínio desenvolve-se através da crítica ao que ele considera dois polos falsos da análise da questão: a concepção da obra de arte na sua universalidade ou na sua singularidade. No primeiro caso, caía-se no dogmatismo, nos cânones do belo com padrões pretensamente válidos em todo tempo e lugar. No segundo caso, a singularidade da arte conduz ao subjetivismo, ao relativismo do belo próprio a cada sujeito, o que ele chama de falso objetivismo e falso subjetivismo.

Mas os antigos estetas, mesmo quando falavam em universalidade e singularidade, estavam situados em certo tempo e espaço históricos - mesmo não admitindo a historicidade do lugar de onde falavam. Konder (2005, p. 60), estudioso que é do autor, diz que "Lukács enfrentou o desafio de pensar a arte e a ciência historicamente, contextualizando as suas manifestações".

Lukács explicita a presença da objetividade e da subjetividade no conhecimento e, especificamente, na obra de arte, através da categoria da particularidade que é o campo das mediações históricas da totalidade social ou do contexto social onde o sujeito se situa e produz pensamentos, ciência, obras de arte etc. Tanto o mundo interior do sujeito quanto o mundo exterior onde os objetos se situam e/ou são produzidos estão presentes no ato de conhecer e de representar o conhecimento em uma das diversas linguagens (línguas, ciências, técnicas, artes etc.) criadas pelo ser humano.

Esta concepção de verdade implica admitir que o conhecimento que podemos ter é sempre aproximativo, dependente da totalidade social e das mediações históricas particulares ao objeto focalizado. Ela difere de uma concepção positivista que toma a visão imediata de um ser, fato ou objeto como conteúdo de consciência e defende a necessidade de a ciência ser neutra, destituída de subjetividade, de valores e ideologias. Em uma visão dialética da realidade, não há 
como separar os julgamentos de fato dos julgamentos de valor. As sociedades, assim como os relatos, a história que constroem sobre as relações de dominação entre os povos, não são regidas por leis naturais, imunes aos sentimentos, aos interesses e às ideologias de cada um. Todorov (1987), a partir do relato do Frei Bartolomé de Las Casas sobre a conquista da América, mostra as relações permeadas pelas ideologias colonialistas de superioridade do homem branco europeu e de negação da humanidade dos nativos encontrados no Novo Mundo.

\section{História, histórias e historicidade²}

São as relações, as tensões, os conflitos entre as mudanças conjunturais e a materialidade estrutural de uma determinada sociedade o tecido social que nos permitem apreender, de forma dialética, o sentido e a natureza das alterações de um determinado momento histórico. A complexidade da apreensão do sentido e natureza destas mudanças se amplia quando o tecido estrutural da sociedade, em suas múltiplas dimensões, apresenta tensões e mudanças abruptas e profundas, sem, todavia, haver uma ruptura do modo de produção. Assim se apresenta a produção da existência em sociedades profundamente desiguais como a brasileira, em países com alto nível de sobre-exploração do trabalho, dependentes das economias do capitalismo central (Marini, 2000). Também o desenvolvimento das ciências e as culturas locais sofrem as influências e as restrições decorrentes das relações assimétricas entre os países.

Como mostra Jameson (1996), a realidade contraditória em que se move a história leva a que todos os referenciais se encontrem em crise face às mudanças bruscas sem precedentes das relações sociais capitalistas e socialistas. Vale dizer, nossas categorias analíticas não dão conta de apreender as mediações e determinações constitutivas das relações sociais. Mas a crise não significa o fim do capitalismo e dos referenciais funcionalistas e positivistas ou críticos. No que concerne ao materialismo histórico, como lembra o autor, este referencial sempre entrou em crise quando o capitalismo, seu objeto de crítica, sofreu mudanças bruscas. Este referencial que se estrutura como crítica radical ao capitalismo, lembra, só pode, portanto, efetivamente acabar quando as relações sociais vigentes forem superadas.

Essa situação de crise do capitalismo explica o retorno, a partir dos anos 1980, na América Latina, às concepções do liberalismo conservador, estruturadas de forma sistemática, neste século, por Frederic Hayek (1987). Divulgada sob as denominações neoliberais e pós-modernas, assistimos à apologia à liberdade do mercado e à crítica a todas as formas políticas que visem à igualdade. Para o autor, a primeira conduz à prosperidade e as segundas, à servidão. O que é amplamente divulgado como sendo a única saída possível para as crises dos países periféricos ao núcleo orgânico do capital, os países ricos. 
Mediante poderosas redes de comunicação, afirma-se que estamos iniciando um novo tempo, o pós-moderno, onde todos os referenciais estão em cheque e as diferenças de gênero, raça, etnia, religião etc. têm maior capacidade explicativa que classes sociais e trabalho assalariado. Trata-se ainda, como assinalam Bourdieu e Wacquant (2000), de uma nova vulgata de organização da linguagem, do pensamento e da ação.

Esta compreensão e, de certa forma, este pressuposto não desconhecem as tensões e os problemas que o próprio materialismo histórico oferece desde sua gênese (Anderson, 1985; Konder, 1988, 1992; 2001) e, sobretudo, os diversos descaminhos trilhados ao longo de mais de século e meio dos quais o economicismo e o viés estruturalista são os mais candentes. Também não ignora as dificuldades intrínsecas de se operar analiticamente com as categorias fundamentais do materialismo histórico - o que não significa ignorar a existência de outros referenciais críticos ou não ao capitalismo.

Os múltiplos relatos que se elaboram sobre os acontecimentos expressam uma visão particular de mundo e uma concepção de história. Desde os primeiros relatos de historiadores registrados pela humanidade, muitas são as escolas de pensamento e suas interpretações dos acontecimentos. Não nos deteremos neste aspecto sobre o qual escreveram renomados historiadores, a exemplo de Cardoso e Brignoli (1979), Fontana (2004) e Aróstegui (2006).

Em termos breves, discordamos de história clássica que alinha fatos e grandes feitos e/ou julga o historiador como alguém neutro, capaz de relatar objetivamente os fatos de seu tempo. Consideramos a escrita da história uma atividade comprometida em termos de valores, interesses, concepções e ideologias de quem relata os acontecimentos. A história se faz com a produção da existência:

O primeiro pressuposto de toda história humana é naturalmente a existência de seres humanos vivos. (...) Esta concepção da história consiste, pois, em expor o processo real de produção, partindo da produção material da vida imediata; e em conceber a forma de intercâmbio conectada a este modo de produção e por ele engendrada (ou seja, a sociedade civil em suas diferentes fases) como o fundamento de toda a história (...) (Marx, 1979, p. 27 e 55).

Entre os trabalhos que tratam de teoria da história e da historiografia de um ponto de vista mais geral, Jurandir Malerba (2006, p. 11) busca fazer uma reflexão sobre o trabalho dos historiadores como "veio da pesquisa histórica concreta", sobre o texto histórico como "produto da arte ou da ciência dos historiadores", na sua prática historiográfica. No século XX, a abertura da história às ciências sociais trouxe a revolução na concepção do tempo histórico e na metodologia da disciplina, como bem exemplifica os Annales. 
Dos questionamentos pós-estruturalistas, depois de 1968, no final dos anos 1980, surge o movimento pós-moderno. Independentemente de ser um conceito sincrético de diferentes teorias, teses e reivindicações, sua origem estaria na filosofia alemã de Nietzche e Heidegger, na adoção dessa filosofia por vários intelectuais franceses, desde a década de 1960, e nas teorias pósestruturalistas da linguagem, originadas na França no mesmo período. O movimento caracteriza-se pelo repúdio à herança moderna da ilustração, de modo especial, à crença na 'razão' e no 'progresso', nas metanarrativas que imporiam direção e sentido à história humana com o significado de emancipação universal. A elas sucedem-se uma multiplicidade de discursos e jogos de linguagem, o questionamento da natureza do conhecimento e a dissolução da ideia de verdade e problemas de legitimação em vários campos.

Das diversas vertentes pós-modernas, o autor extrai “duas grandes teses ou pressupostos". A primeira, a do antirrealismo epistemológico, retira do conhecimento histórico quaisquer pretensões de se relacionar com um passado real. A história seria "uma espécie de literatura e faz do passado nada mais, nada menos do que um texto". A segunda tese é a do narrativismo "que confere aos imperativos da linguagem aos tropos ou figuras dos discursos, inerentes ao seu estatuto linguístico, a prioridade na criação das narrativas históricas". Nesta concepção, a ficção dos escritores em nada difere das narrações dos historiadores. O autor conclui que o que está em questão é a própria objetividade do conhecimento e os limites estruturais da verdade de seus enunciados. Se o pós-modernismo contribuiu para a derrubada de alguns dogmas, de alguns "postulados férreos" e de "certas versões marxistas esquemáticas e de reminiscências cientificistas", pouco contribuiu para a teoria da história e para a historiografia (p. 13-14).

Falando sobre a prática da crítica historiográfica, Malerba afirma o caráter auto-reflexivo do conhecimento histórico, cuja característica básica é a própria historicidade. Discutindo “o caráter da subjetividade inevitável" defende que ela deve compor a necessária objetividade do conhecimento e concorda com Marc Bloch que "a fonte geradora da historiografia é a necessária retificação das versões do passado histórico operada a cada geração" (Malerba, 2006, p. 16-18).

Dos livros de Pierre Vilar $(1985,1992)$ sobre a história e o que é pensar historicamente extraímos algumas ideias mais gerais que nos ajudam a refletir sobre os estudos comparados. O autor lembra que "Dado que o passado é passado, quer dizer, não repetível por definição, confunde-se para nós com o que dele foi transmitido. O conhecimento confunde-se assim com a matéria" (Vilar, 1985, p. 17-18). A questão que se coloca é como raciocinar sobre uma matéria sobre a qual não temos mais o poder de intervir? Ao que, mais adiante, responde: 
O que torna possível a história é a coexistência e a combinação do testemunho subjetivo que nos conta o que pretendiam fazer os atores da história política, com o documento objetivo (não apenas vestígios e objetos, mas dados estatísticos conservados, escritos redigidos por razões práticas e não para ilustrar uma minoria dirigente) (Vilar, 1985, p. 29, grifos do autor).

Para Vilar, a historicidade no trato dos acontecimentos está em situá-los no tempo e no espaço, nas sociedades em que ocorrem: “Mas querer pensar a sociedade, isto é, sua natureza, e pretender dissertar sobre ela exige uma contínua referência as suas dimensões temporais". Pensar historicamente "implica situar, medir, datar, sem cessar" (Vilar, 2005, p. 21, grifos do autor). ${ }^{3}$

\section{História e comparativismo}

Assim como o conhecimento, a verdade e a história são objeto de diferentes concepções, os estudos comparados têm várias vertentes de análise. Antes de iniciarmos a apresentação de alguns trabalhos que elaboramos sobre os estudos comparados, vamos expor brevemente, o pensamento de alguns de seus estudiosos em educação (Le Thánh Koi, 1983; Nóvoa, 1998).4

Segundo um autor clássico da educação comparada, Le Thánh Koi (1983), a educação comparada nasceu da observação dos viajantes e remonta a Xenofonte no século IV a. C., quando ele expõe os sistemas de educação aristocrático, guerreiro e moral dos jovens persas, comparando à educação ateniense, que era mais física e estética. Sem nos determos nas análises que ele empreende através dos séculos, a publicação Esquisse et vues preliminares d'un ouvrage sur l'education comparée, de Marc Antoine Julien, em 1917, é considerada um marco nos estudos comparados no sentido de tornar-se uma ciência. A reflexão de Le Thánh Koi busca explicitar um método científico da educação comparada e de sua relação com outras ciências. Sobre o primeiro aspecto, ele parte de Bereday (1964), que define quatro fases em seu método comparativo em educação: a descrição, a interpretação, a justaposição e a comparação. A seguir, tendo como referência o paradigma das ciências experimentais, ele apresenta seu método com as seguintes etapas: a identificação do problema, a formulação de hipóteses, a coleta, o tratamento e a análise dos dados, a verificação da hipótese e, como última etapa, a generalização. Sobre o segundo aspecto, destaca a relação com "as ciências dos processos pedagógicos", a psicologia, a sociologia, a economia, a história, a política, concluindo que "Cada ciência privilegia um aspecto do real para melhor apreendê-lo com seus próprios métodos e técnicas" (Bereday, 1964, p. 44), o que acaba sendo uma visão segmentada da realidade social, em oposição a uma visão da realidade como uma totalidade social articulada nas suas múltiplas mediações. 
Em síntese, o autor é aberto aos diferentes caminhos da produção do conhecimento, perpassando os diversos métodos estatísticos e matemáticos de análises qualitativas e quantitativas, inclusive a dialética, expondo suas ideias básicas e apontando seus limites. Mas não se posiciona conclusivamente sobre nenhum deles exceto ao expor, como indicamos anteriormente, as etapas do método científico para os estudos comparados.

Outro autor de que nos aproximamos foi Antonio Nóvoa (1998) e seu livro Histoire \& Comparaison (Essais sur la Educatión). O texto é produto de uma pesquisa desenvolvida nos Estados Unidos e tem como critério de referência os aspectos teóricos e metodológicos, buscando relacionar, ao longo de cinco capítulos, "um discurso histórico e comparativo" (...) com o fim de identificar os problemas da pesquisa histórica na elaboração conceitual sobre esses problemas (Nóvoa, 1998, p. 9 e 14).

A relação espaço-tempo marca a organização do campo da história. No mundo atual há um rompimento das concepções tradicionais de tempo, espaço, periodização:

A pesquisa histórica se deslocou de uma inserção local para os enquadramentos nacionais, de uma territorialização para um jogo complexo de interdependências em nível mundial. Passou dos acontecimentos (ou a sucessão de acontecimentos) para a delimitação das épocas, de uma periodização estrita para a abertura da fluidez dos tempos sempre mais longos (Nóvoa, 1998, p. 15).

Delineou-se uma nova visão do objeto da história, que não se limita a reconstituir o passado, mas a entender como ele chegou ao presente, influenciando nossas concepções, nossas maneiras de pensar e nossa linguagem.

Nos Estados Unidos, se encontra, desde o século XIX, “a ideia e o ideal de objetividade". Assim se explicariam os critérios de cientificidade e de prestígio no interior da comunidade de historiadores, organizados a partir de "uma escala de afastamento/aproximação em relação a uma 'verdade objetiva' sobre o passado" (Nóvoa, 1998, p. 17, grifos do autor).

Esse quadro onde os historiadores eram legitimados como empiristas em busca de fatos objetivos e da história como uma grande "narrativa do progresso" foi posto em discussão dando origem a várias perspectivas históricas que não se colocam mais em termos de "verdades científicas", mas em termos de construção de "discursos verídicos". A história se torna, assim, uma entre outras formas discursivas de compreensão do social. Trata-se de uma nova visão da 'subjetividade' de forma que "conhecimento e valores não existem fora dos sentidos que os seres humanos constroem" (Ross, 1994 apud Nóvoa, 1998, p. 17-18).

“Simultaneamente, assiste-se à recusa, pelos historiadores, das análises causais e à valorização da complexidade, embora mais em nível conceitual 
que metodológico." O autor ressalta que a dissolução dos limites da história está bem presente na obra de Hayden White, "principalmente quando ele pretende que todo discurso histórico seja um escrito poético" (Nóvoa, 1998, p. 18-19, grifos do autor).

O texto contém outras especificações sobre a história na literatura especializada nesse campo nos Estados Unidos. Para fins deste estudo que busca chegar aos estudos comparados, principalmente, na educação, cabe destacar que "Os dilemas da história da educação são os mesmos da história” (Nóvoa, 1998, p. 22), seja quanto às interrogações, como quanto aos processos de legitimação dos próprios caminhos, tanto no trabalho histórico, quanto na ação educativa.

Vejamos alguns pontos destacados pelo autor:

O comparativismo está em busca de novas questões que lhe permitam construir outras histórias. (...) Nossas epistemologias não podem mais ignorar alguns dos desafios da 'virada pós-moderna', principalmente que nada pode ser conhecido de forma segura e que não existe mais uma teleologia da história. (...) A educação comparada deve romper com seu espaço tradicional de referência, o Estado nacional, abrindo-se à pesquisa da diversidade de situações e de contextos (Nóvoa, 1998, p. 52).

Nóvoa (1988, p. 54) conclui que se trata de “explicar a construção histórica do campo nas suas relações com os saberes e os poderes; compreender as fragilidades, mas também as potencialidades de um projeto científico que mantém-se na atualidade". O interesse renovado pela educação comparada estaria nas problemáticas educativas comuns a vários países em decorrência da globalização econômica; na crise do Estado nação e na emergência de novos espaços de identidade cultural em plano local e em diversas regiões do mundo; e a internacionalização do mundo universitário e da pesquisa científica. Isso requer não simplesmente, como querem alguns, uma educação comparada mais útil, mais pragmática, mais próxima das decisões políticas, mas, sim, mais aprofundamento teórico e conceitual.

Consideramos que há atualidade nesses aspectos de sua reflexão, além da legitimidade científico-acadêmica do autor. Mas, de nosso ponto de vista, suas posições tangenciam as questões principais da sociedade e da educação. Filiam-se - com reservas, é verdade - às posições pós-modernas que fragmentam o conhecimento, omitem a existência das classes sociais e o fato fundamental das desigualdades sociais e da dominação dos países desenvolvidos e dos organismos internacionais nos projetos homogeneizadores para os países periféricos ao núcleo orgânico do capital.

Tanto o pensamento positivista de uma ciência social neutra e objetiva quanto a defesa pós-moderna da subjetividade como critério de verdade são aproximações metafísicas de problemas que têm uma materialidade contun- 
dente na vida e na educação de milhões de pessoas. São condições econômicas, sociais e políticas que balizam a vida dos povos e que devem constar dos critérios teórico-práticos da produção do conhecimento e dos estudos comparados nas ciências sociais e na educação. Esta é a base de nossa aproximação comparativa conforme vou relatar na próxima seção deste estudo.

\section{Estudos comparados em educação na América Latina: uma tomada de posição}

A educação comparada tem uma tradição de natureza sistêmica na América Latina. Países inteiros e seus indicadores de escolaridade, de exclusão escolar, de analfabetismo e outros problemas são tratados de uma forma estatística (quantidade que dá a dimensão dos problemas). Mas é um tratamento reducionista dos problemas à sua descrição, na forma aistórica, descontextualizada, como se os números pudessem expressar, por si mesmos, algo independente das condições que lhes deram origem. São dados isolados do desenvolvimento social, econômico, cultural e educacional, da história de cada país, dentro do modelo dos grandes surveys dos anos 1970 e, ainda hoje, em estudos internacionais. De forma que fenômenos de grande densidade social são reduzidos a aspectos qualitativos ou a um conjunto de dados quantitativos.

A este limite básico, de natureza epistemológica, e à questão política das ideologias assépticas, de suposta neutralidade científica (positivistas, evolucionistas e conservadoras) veiculadas por muitos estudos, soma-se a influência de generosos recursos concedidos por organismos internacionais. Destinados à realização de pesquisas deste teor e para a implantação de programas junto aos sistemas públicos de ensino, conduziram a educação comparada à insuficiência de respostas para os principais problemas de educação na América Latina (Ciavatta Franco, 1992a).

O mito da neutralidade científica pautou o nascimento das ciências experimentais e as ciências sociais, elevando a verdade científica a um status soberano sobre os demais conhecimentos. Os estudos comparados foram também afetados por essa pretensa objetividade do conhecimento apoiado na observação e no registro dos dados e em métodos quantitativos de análise.

O trabalho que deu motivo à organização do livro teve origem na minha prática docente em educação brasileira. Estávamos em meados dos anos 1980 e vislumbrava-se a democratização da vida social e política no Brasil. Discutíamos e nos organizávamos em congressos e mobilizações por uma nova Constituição Federal (que veio a ser aprovada em 1988) e por uma nova Lei de Diretrizes e Bases da Educação (que somente veio a ser aprovada em 1996, durante o governo neoliberal de Fernando Henrique Cardoso). Os estudos da educação brasileira ${ }^{5}$ que, durante a ditadura, pautaram-se por um viés legislativo- 
tecnicista, começavam a ter uma prática diferenciada, que incluía os aspectos sociais e políticos da educação.

Professora recém-concursada em um departamento da Faculdade de Educação da Universidade Federal Fluminense (UFF), tendo alguma experiência de pesquisa em educação na América Latina, na falta de uma professora do quadro de Estudos Comparados de Educação na América Latina, fui convocada a assumir a disciplina eletiva no segundo semestre de 1985. Além de dois anos de pesquisa em educação técnica na América Latina (Argentina, Brasil e Colômbia), eu tinha a experiência de algumas viagens internacionais pelo continente e descobrira os laços do Brasil com o outro lado dos Andes (particularmente Peru, Bolívia, Colômbia, Chile e Equador), que era a situação de pobreza de nossos povos, a herança colonial da dominação, primeiro, pelos europeus e, depois, pelos americanos.

Não sabia ainda como conduzir a disciplina, mas tinha claro que os Estudos Comparados deveriam ter o contexto político que imprimíamos às aulas de educação brasileira. O desafio estava em escolher um ou dois países e conhecer um pouco de sua história social, política e econômica para contextualizar a educação e compreender os processos históricos de seu desenvolvimento.

Do ponto de vista teórico-metodológico, comecei a buscar conhecer estudos críticos sobre a abordagem sistêmica da comparação. Mas o processo foi lento, apenas em 1992 concluí o artigo-base do livro, inspirado na 'questão do outro' (Todorov, 1987) e em textos da historiadora argentina Adriana Puiggrós, do comparatista italiano Ettore Gelpi, do economista Jacques Velloso, dos antropólogos Franz Boas e Roberto da Matta e dos cientistas sociais Agustín Cueva e Guadelupe Bertussi, para o tratamento historicizado dos temas. 6 O livro (Ciavatta Franco, 1992a) se estruturou em torno de uma concepção histórica de educação comparada e de algumas análises que se pautam por essa concepção.

O primeiro artigo é um texto teórico-metodológico (Ciavatta Franco, 1992b). A primeira questão considerada é o desequilíbrio intrínseco que se estabeleceu desde o início da colonização entre os nativos e os colonizadores. Criou-se, artificialmente, uma 'assimetria de humanidade' onde ser humano era ser igual aos europeus. Os nativos não parecem homens e, se o são, são bárbaros inferiores. Não falam a língua dos brancos. O que era um problema inicial de comunicação se tornou uma forma de convivência baseada na opressão, escravidão e servidão de comunidades inteiras.

Os colonizadores impuseram ao continente sua língua, seus hábitos, sua arquitetura, seus valores, sua cultura. Séculos depois, outros europeus e os americanos trouxeram novos valores, costumes, objetos e sua cultura literária e científica. Quando nos comparamos com os países avançados, quais sãos os parâmetros dessa comparação? Sua ação poderosa e extensiva, seus recursos ou sua história? (Ciavatta Franco, 1992b). 
Ettore Gelpi (1987) aponta o estudo das grandes transformações do mundo da produção, da divisão internacional do trabalho, da questão do Estado e da hegemonia de alguns países em nível mundial como questões importantes para o desenvolvimento dos estudos comparados em educação. O que tem consequências no tratamento dos fenômenos educacionais como fatos sociais e, portanto, no estudo da educação a partir das ciências sociais: da história, da sociologia, da economia, da política.

É uma questão de método tratar cada fenômeno além de sua aparência, do primeiro contato, da descrição que é importante na sua identificação, mas não contém a explicação das causas não aparentes que o constitui como “síntese de múltiplas determinações" (Marx, 1977, p. 229).

Os demais estudos são pautados por essa visão contextualizada dos problemas. Mostram algumas questões da educação na América Latina onde a visão da totalidade social em que ocorrem são os países, sua história, seu desenvolvimento econômico e cultural, sua política etc. O primeiro (Bertussi, 1992) trata do analfabetismo na América Latina, comparando-o à alfabetização de toda a população em Cuba após a revolução. Historicamente, foram as condições de vida e de cidadania proporcionadas pelo Estado socialista que gerou uma outra qualidade de vida e de educação. O estudo mostra uma série histórica de dados (1950 a 1980) que não são interpretados apenas nos aspectos percentuais, mas no seu significado social e político.

O segundo texto trata de educação e trabalho em Cuba e no Brasil. A pesquisa realizada em Cuba e no Brasil busca mostrar a união entre estudo e trabalho em Cuba, onde se tenta eliminar o caráter mercantil da educação. A combinação estudo e trabalho, assim como trabalho manual/trabalho intelectual, estão presentes em todos os níveis escolares. Diferente é a qualificação profissional e técnica no Brasil, a relação estudo e trabalho com vistas ao atendimento das necessidades da indústria, sob a forte presença dos empresários e dos interesses capitalistas de formação de mão-de-obra. Os anos 1980, os ventos da redemocratização, a nova Constituição e a LDB em tramitação no Congresso Nacional nessa década (quando o texto foi escrito) traziam a defesa da educação politécnica (Ciavatta Franco, 1992c).

Os últimos três artigos sobre a educação socialista (Puiggrós, 1992) detêmse em analisar o regime socialista soviético e a educação, seus avanços em relação ao sistema capitalista e aos limites do próprio sistema socialista na ex-URSS. Cabe destacar que os textos foram escritos antes da queda do regime socialista em 1989 e fazem uma crítica contundente à modernidade que unia a educação capitalista e a educação socialista a partir da base stalinista, contrariando a orientação marxista de base "humanista e antitecnocrática da educação politécnica, do trabalho produtivo como elemento pedagógico e da escola unitária" (Puiggrós, 1992, p. 82). 


\section{Formação profissional para o trabalho incerto: um estudo comparativo Brasil, México e Itália}

Este tema representou um desafio adicional (Ciavatta Franco, 1998). Tratavase de um tema de estudo empírico: a formação profissional de trabalhadores na visão de seus sindicatos em três países, Brasil, México e Itália. Para atender à necessária contextualização, era preciso entender as mudanças sociais e do trabalho em meados dos anos 1990, quando estavam em expansão as políticas econômicas neoliberais com a ideologia da privatização, do Estado mínimo, do corte de custos. No âmbito das empresas, ocorria a reestruturação dos processos produtivos, da produção flexível, e o modelo japonês com a nova organização do trabalho, o uso da microeletrônica, da informática, o 'enxugamento' do sistema com os cortes de pessoal e a desregulamentação das relações de trabalho (chamada de flexibilização).

Tentar apreender essas mudanças estruturais em três países para pensar a formação dos trabalhadores foi um trabalho árduo. E somente foi possível através de muitas entrevistas com sindicalistas de cada país. A incerteza do vínculo empregatício e do trabalho e a ressignificação da formação dos trabalhadores eram temas constantes. Ao lado deles, as políticas governamentais de qualificação através de uma multiplicidade de cursos profissionais. Também eram abundantes livros e artigos sobre a reestruturação produtiva, o modelo japonês, o discurso da empregabilidade e da pedagogia das competências.

No México, através de seus principais sindicatos, os eletricitários e os petroleiros, entrevistei trabalhadores empenhados nos processos formativos como moeda de negociação com as empresas que se modernizavam. Na Itália, programas para trabalhadores em um sistema descentralizado e, em grande parte, gerido por organizações não governamentais e confessionais, ofereciam a formação como atenuante do desemprego, mas orientada pelas demandas econômicas regionais.

No Brasil, semelhante ao México e a outros países latino-americanos, avançava-se no padrão de uma economia globalizada, com o sistema toyotista de produção ao lado de setores produtivos tradicionais e a convivência com grandes segmentos de trabalhadores semianalfabetos e analfabetos. A principal diferença entre o país europeu e os dois países da América Latina era o baixo nível de escolaridade dos trabalhadores nos dois primeiros. O que se traduzia, frequentemente, em cursos breves, iniciais, portadores da ilusão de capacitação para novos empregos cuja oferta reduzia-se progressivamente.

Na Itália, à semelhança de outros países europeus do capitalismo central, educação básica gratuita e obrigatória até o nível médio, para todos os jovens, dava à população trabalhadora a capacidade de incorporar as novas propostas de trabalho e formação, as novas tecnologias, além da 
proteção social do Estado como o seguro-desemprego prolongado e a qualidade dos demais serviços sociais.

Uma das questões em destaque em todos os três países era pensar novas relações de trabalho e sindicais que sinalizassem os novos processos em curso, de modo a antecipar o futuro e, ao mesmo tempo, criar uma lógica de participação e de negociação, de estratégia sindical. Como essa nova lógica poderia ser assimilada pelos sindicatos em países como o Brasil e o México, em que as relações de trabalho ainda são de extrema exploração da maioria da população economicamente ativa?

\section{Quando nós somos o outro: revisitando as questões teórico-metodológicas sobre os estudos comparados}

Meu primeiro trabalho sobre estudos comparados (Ciavatta Franco, 1992a) nasceu da consciência de povos colonizados que emergiu com força, na América Latina, na comemoração dos 500 anos da 'conquista' (1592-1992), ou como queriam os espanhóis, da 'chegada' dos europeus ao continente. Para mim, essa consciência se tornou mais aguda com a vivência prolongada em um país europeu, a Itália. Ficou mais clara a percepção da presença incômoda dos imigrantes africanos nas ruas e os direitos e benefícios restringidos para os extracomunitários, isto é, para aqueles que não pertenciam à União Européia (Ciavatta Franco, 2000a, 2000b).

Voltamos à tomada de posição historicizada do primeiro texto e ampliamos a análise dos estudos comparados nas ciências sociais. Do primeiro texto constam o expansionismo moderno e o desenvolvimento das ciências sociais. Abordamos a influência da sociologia de Durkheim e do positivismo de Augusto Comte nos métodos de pesquisa dos fenômenos sociais. A redução positivista-funcionalista dos fenômenos à dimensão quantitativa "tem como finalidade produzir ilusões sobre a realidade complexa que acaba sendo simplificada e suscetível de adequar-se aos modelos estabelecidos teoricamente" (Puiggrós, s.d., p. 5-6). Analisam-se os sistemas educativos como se fossem objetos isolados, destituídos de seus conteúdos sociais, políticos e econômicos que lhe atribuem um significado. São criadas relações lineares de causa e efeito, são realizadas comparações entre aspectos ou partes dos sistemas educativos dos diferentes países, fora da condição estrutural na qual se encontram suas raízes e suas possíveis explicações (Puiggrós, s. d., p. 5-6).

De modo especial, vimos o papel da antropologia cultural como aliada do expansionismo colonialista europeu no século XIX, colocando os povos em uma escala evolutiva onde os europeus representavam as culturas superiores face aos demais povos primitivos, indígenas, colonizados. Se a antropologia deu, nos seus primeiros trabalhos, oportunidade à legitimação da 
discriminação entre pessoas e entre povos, foi também a antropologia a primeira ciência a pôr em discussão 'o outro' e a valorizar a diferenciação, a diversidade, a alteridade e o papel que estas categorias assumem na história de nossa espécie e em tantos aspectos de nossas sociedades.

Já no século $\mathrm{XX}$, os estudos sobre a dependência dos países latinoamericanos em relação aos países desenvolvidos permitiram vislumbrar um pensamento que buscava refletir sobre os problemas latino-americanos a partir de nossa própria realidade, distanciando-se do olhar externo. A 'teoria da dependência', com suas verdades, meias-verdades, erros e acertos, seria uma tentativa de oferecer ao mundo acadêmico e aos políticos uma visão com alguma autonomia em relação à economia, à cultura e à ciência produzida nos países ricos, às assimetrias das relações norte-sul.

Ampliamos a pesquisa sobre os métodos comparativos entre historiadores e sociólogos, entre aqueles que se identificam com a sociologia histórica ou com a história social, e os que utilizam o método na ciência política, buscando nessas ciências a gênese e o desenvolvimento dos estudos comparados.

A história fez um percurso semelhante ao da antropologia, colecionando fatos por longo tempo e buscando as leis gerais da evolução humana. A história comparada, se a vemos como um dos paradigmas para os estudos comparados em educação, apresenta-se como um campo onde são muitas as orientações metodológicas e as concepções de história.

Comentando o pensamento de um dos fundadores da École des Annales, Marc Bloch, Pietro Rossi (1994a) considera que se tratava de responder ao desafio do desenvolvimento das ciências sociais, sobretudo a sociologia de Durkeim, de transformar os estudos históricos em uma disciplina científica através da definição de uma metodologia rigorosa, através do uso das fontes e da reconstrução dos acontecimentos do passado. Para Bloch, o ambiente era considerado um produto da ação transformadora dos grupos que nele tinham se estabelecido e, portanto, era um produto histórico.

O desenvolvimento da história comparada está muito ligado ao desenvolvimento da sociologia, onde o método comparativo teve origem (Burke, 1980). A sociologia se preocupa em estabelecer as leis gerais, enquanto a história se preocupa com os eventos particulares, aqueles que não se repetem, que são únicos. Teria sido a sociologia a oferecer ao historiador não apenas os conceitos, mas também os instrumentos metodológicos, tais como a observação, a análise cruzada, a análise de conteúdos e o método comparativo.

Rossi (1994b) faz uma análise das relações da história comparada com as concepções gerais da história e com as outras ciências sociais, particularmente a sociologia. Para o autor, a historiografia buscou na comparação a superação do ideografismo de base historicista, enquanto as ciências sociais buscaram, na referência à história, dar conteúdos menos genéricos aos seus modelos, mediante a análise dos 'casos' particulares. São abandonadas as 
colocações macro-históricas e se elaboram modelos mais específicos que não se referem à sociedade global, mas a contextos definidos.

A ciência política nasceu como uma disciplina especializada nas instituições políticas comparadas, no final do século XIX. Seu ponto de partida foi o mesmo da sociologia durkheimiana, a impossibilidade de produzir os fatos sociais em laboratório. O trabalho comparativo também se inspirou no método das variações concomitantes, de modo a interpretar as variações de um determinado objeto social relacionadas com as diferenças comprovadas de determinado fator em igualdade de circunstâncias. Este método, chamado de 'método comparativo clássico', entrou em crise nos anos 1960 por suas fragilidades metodológicas, principalmente devido às dificuldades de análise política postas pela descolonização e a emergência de grande número de Estados novos, que refletiam uma ordem política diferentes do mundo ocidental.

São muitas as críticas que cercam os estudiosos dos métodos comparativos. Uma crítica estaria no universalismo e no etnocentrismo do método comparativo na concepção tradicional dos estudos comparados. Quanto à crítica à análise cultural e à sociologia histórica, o núcleo do problema está na concepção causal como modelo explicativo. Em síntese, a visão histórica supõe a dialética, a transformação própria à natureza e ao ser humano. $\mathrm{O}$ uso de variáveis (medidas pela variação de um valor) e da causalidade (como relação de causa e efeito), próprio às ciências experimentais, aos métodos estatísticos e às abordagens positivistas, não permite que se avance além dos limites mecanicistas impostos ao tratamento dos fenômenos sociais pelo uso dessas categorias.

\section{Estudos comparados sobre formação profissional e técnica: uma breve revisão de literatura}

Este trabalho é fruto de uma pesquisa de estado da arte sobre artigos publicados em periódicos especializados sobre formação profissional e técnica nas décadas de 1980 e 1990 (Ciavatta, 2006). Seu foco principal não são as questões teórico-metodológicas, mas os conteúdos das políticas educacionais sobre essa modalidade de formação.

No entanto, aparecem nos textos examinados algumas posições teóricoconceituais. Há uma pluralidade de tendências e de posições em torno de uma educação frequentemente dual, onde o mercado de trabalho prevalece como horizonte e finalidade da formação, o que significa uma visão de curto prazo. Destacam-se as experiências orientadas pelos organismos internacionais, no sentido da "homogeneização das referências intelectuais e técnicas trazidas pela difusão dos modelos" dessas organizações (Casanova apud Cunha, 2000, p. 48). No mesmo contexto, Wilson (apud Cunha, 2000) registra uma 
concepção etnocêntrica e três vetores tendenciais: descentralização (diminuição das instâncias públicas), setorização (ou fragmentação da educação técnica e profissional), privatização (transferência da administração das instituições públicas para os empresários) e diversificação das fontes de financiamento (do público para o privado).

Sob a influência das políticas neoliberais, essa tendência se acentua nos anos 1990. O Chile teria atuado como se fora um laboratório do modelo para a América Latina. Em países como Brasil, Chile e Argentina, teria havido, nas duas décadas, uma tendência a aumentar a cobertura escolar sob a pressão das camadas de baixa renda e a ampliação da escolarização das mulheres (Cunha, 2000). Também teria crescido o protagonismo dos Ministérios do Trabalho no campo da formação, a exemplo do que ocorreu no Brasil (Weinberg, 1999).

Um outro conjunto de trabalhos trata da formação profissional e técnica nos países desenvolvidos (Alemanha, Reino Unido, França, Estados Unidos, Japão). Chamam a atenção, semelhantes ao estudo que realizamos na Itália, os encaminhamentos duais para uma das redes, de formação geral ou de formação profissional e técnica. A diferença em relação aos países do hemisfério sul está na universalização do Ensino Médio público que dá uma base formativa onde o conhecimento, para fazer face às inovações tecnológicas, é mais facilmente assimilável pelos trabalhadores escolarizados até o nível médio de ensino.

Concluímos que, metodologicamente, alguns estudos comparados avançaram na direção de sua contextualização na história social e econômica de cada país. Todavia, ainda é débil a crítica à forma perversa como as necessidades da produção capitalista se traduzem em processos de formação profissional. Impõem-se soluções paliativas e cria-se o consenso para sua aceitação em lugar da universalização de uma educação fundamental e média, pública, gratuita, de qualidade para toda a população. E reduz-se a formação profissional a treinamentos, a uma preparação funcional às empresas que priva os trabalhadores dos fundamentos histórico-sociais e científico-tecnológicos, a exemplo do que propõe a educação politécnica, a escola unitária e a formação integrada.7

\section{Considerações finais}

Este texto teve por objetivo geral contribuir para a reflexão e a prática dos estudos comparados nas ciências sociais e, de modo especial, na educação. Assumimos que a comparação é um processo constante na atividade intelectual, tanto nos trabalhos acadêmicos como nos aprendizados da vida cotidiana. Através de analogias distinguimos uns seres dos outros, nomeamos de modo distinto cada um deles. A questão do outro e do reconhecimento da 
alteridade é a base do reconhecimento de si mesmo e da própria identidade. Essa concepção nos obriga a pensar em seres em relação, como partes de uma ou mais totalidades sociais, dependendo da questão em foco do mundo da natureza, da cultura e dos sujeitos sociais envolvidos.

Vivemos um momento histórico em que afloram três questões que, através de múltiplas mediações sociais, podem dar sentidos diferenciados ao ato de comparar no campo da produção do conhecimento. A primeira questão eclodiu na imprensa brasileira na segunda metade de 2008: é a crise financeira do capitalismo com desdobramentos ainda imprevisíveis em 2009. Os rendimentos financeiros multiplicados como que se volatilizam e escancaram ao cidadão comum os ganhos exorbitantes dos bancos, de seus executivos e dos ativos dos aplicadores em todo o mundo. Ao mesmo tempo, as empresas têm reduzido seus investimentos produtivos, cresce o número de demissões e de desempregados, sem que se tenha claro o horizonte que se delineia. Constata-se a desregulamentação da circulação de capitais que atingiu níveis incontroláveis. Ao lado do socorro financeiro bilionário aos bancos e às grandes empresas, os analistas preveem que os Estados e os organismos internacionais devem voltar, talvez, à doutrina keynesiana e estabelecer novos controles à circulação ao jogo financeiro.

O segundo fato a chamar a atenção é o movimento oscilante de algum tipo de união entre os países latino-americanos da região sul, até então, a exemplo do México, parceiros dos Estados Unidos em situação de assimetria e de poder competitivo. Alternam-se várias áreas de interesse comercial e político, marcadas por atritos. Damos apenas alguns exemplos: entre o Brasil e a Argentina (pontos de vista diferentes sobre a taxação de importados), entre o Brasil e o Equador (sobre o pagamento de empréstimos para a construção de barragens), entre o Brasil e a Bolívia (sobre investimentos e tarifas do gás boliviano) e entre o Brasil e a Venezuela (sobre políticas internacionais). Para Cuba, parece convergir a solidariedade de todos esses países que, se não se unem em um Mercosul idealizado, dialogam, disputam e sentenciam buscando maior aproximação que os fortaleça nas árduas relações com o império norte-americano.

O terceiro fato que consideramos significativo neste momento são mobilizações nas ruas em muitas cidades do mundo. Em um tempo em que a consciência dos problemas é pautada pelos meios de comunicação, esses fatos não incidem diretamente sobre os estudos comparados, mas estabelecem ideias, acordos, iniciativas, modelos, legitimidades, formas de financiamento que somente se tornam compreensíveis se inseridas em seu contexto.

A sociologia, a história, a antropologia, a ciência política e a educação foram longamente influenciadas pelo desenvolvimento de outras ciências e da vida política. No caso da educação, na América Latina e em outros países do Terceiro Mundo ou dos países da periferia do capital, conforme as 
análises mais recentes, políticas e leis educacionais foram decorrentes de acordos e da intervenção dos organismos internacionais.

Assim, muitas 'verdades' foram defendidas e outras tantas criticadas. Os autores dos estudos comparados que apresentei têm posições particulares sobre como apreender e interpretar os fenômenos sociais dos diversos países. Nas pesquisas que desenvolvi com objetivos teórico-práticos de comparação no campo trabalho e educação, pautei minhas análises por uma visão historicizada dos fenômenos, concebendo a história, no seu sentido mais geral, como a produção social da existência. Os dados quantitativos dão a dimensão dos problemas, mas não os explicam, apenas os descrevem com algumas de suas características. As relações, as tensões, os conflitos entre as mudanças conjunturais e a materialidade estrutural de uma determinada sociedade compõem o tecido social que nos permite apreender, de forma dialética, o sentido e a natureza dos acontecimentos em um determinado momento histórico.

\section{Notas}

1 Professora Titular associada ao Programa de Pós-Graduação em Educação da Universidade Federal Fluminense (UFF), Coordenadora do Grupo de Pesquisa Trabalho e Educação junto ao Conselho Nacional de Desenvolvimento Científico e Tecnológico (CNPq), Professora Visitante da Universidade do Estado do Rio de Janeiro (Uerj), Bolsista de Pesquisa (CNPq). Doutora em Ciências Humanas (Educação) pela Pontifícia Universidade Católica do Rio de Janeiro (PUC-Rio). <mciavatta@terra.com.br>

Correspondência: Universidade Federal Fluminense, Faculdade de Educação, Campus do Gragoatá, Avenida Visconde do Rio Branco, 860, Sala 526, Niterói, Rio de Janeiro, Brasil, CEP 24210-330.

2 Parte destas reflexões tem por base Ciavatta, 2007.

3 Nossa tradução: "Pero querer pensar la sociedad, es decir, su naturaleza, y pretender dissertar sobre ello, exige uma continua referencia a sus dimensiones temporales" (...) "implica situar, medir, fechar, sin cessar."

4 Por razões de espaço e para não sermos mais superficiais no tratamento dos autores, não nos ocupamos de alguns estudiosos do assunto, tais como a coletânea de LopezValverde (2000), que inclui nomes como Miguel Pereyra e Jurgen Scriewer; a coletânea de Altbach e Kelly (1989), que inclui, entre outros, Miguel Pereyra, Michael Apple e Martin Carnoy; Lourenço Filho (1961); Bonitatibus (1989); Silveira (1992).

5 Originalmente, a disciplina, na Universidade Federal Fluminense, para a qual eu fizera um concurso docente para professor assistente (1984), chamava-se Estrutura e Funcionamento do Ensino. 
6 Ver a citação completa das referências dos autores em Ciavatta Franco, 1992b.

7 Quando falamos em educação politécnica, nos referimos à combinação estudo e trabalho, segundo a concepção de Marx e dos primeiros tempos da Revolução Russa; a escola unitária refere-se à concepção gramsciana da escola universalizada para preparar produtores/dirigentes; a formação integrada refere-se à alternativa da integração entre o Ensino Médio/formação geral e a educação profissional (decreto n. ${ }^{\circ}$ 5.154/04, incorporado ao texto da LDB n. ${ }^{\circ}$ 9.394/96) (ver Ciavatta, 2005).

\section{Referências}

ALTBACH, Philip G.; KELLY, Gail. Nuevos enfoques en educación comparada. Madrid: Mondadori, 1989.

ANDERSON, Peter. A crise da crise do marxismo. São Paulo: Brasiliense, 1985.

ARÓSTEGUI, Julio. A pesquisa histórica. Teoria e método. Bauru: Edusc, 2006.

BACHELARD, Gastón. Epistemologia. Trechos escolhidos. Rio de Janeiro: Zahar, 1977.

BEREDAY, George G. F. Comparative method in education. New York: Holt, Rineart and Winston, 1964.

BERTUSSI, Guadelupe T. Analfabetismo na América Latina: uma análise comparada. In: CIAVATTA FRANCO, Maria (Org.). Estudos comparados em educação na America Latina. São Paulo: Livros do Tatu/Cortez, 1992.

BONITATIBUS, Suely G. Educação comparada. Conceitos, evolução, métodos. São Paulo: E.P.U., 1989.

BOURDIEU, Pierre; WACQUANT, Loïc. A nova bíblia do Tio Sam. Le Monde Diplomatique, edição brasileira, ano 1, n. 4, ago. 2000.

BURKE, Peter. Sociologia e história. Porto: Edições Afrontamento, 1980.

CARDOSO, Ciro F.; BRIGNOLI, Hector P. Os métodos da história. 2. ed. Rio de Janeiro: Graal, 1979.
CIAVATTA FRANCO, Maria (Org.). Estudos comparados em educação na América Latina. São Paulo: Livros do Tatu/Cortez, 1992a.

Estudos comparados em educação na América Latina. Uma discussão teóricometodológica a partir da questão do outro. In: _ (Org.). Estudos comparados em educação na America Latina. São Paulo: Livros do Tatu/Cortez, 1992b.

. Questões polêmicas da relação entre trabalho e educação na sociedade industrial. In: _. (Org.). Estudos comparados em educação na America Latina. São Paulo: Livros do Tatu/Cortez, 1992c.

Formação profissional para o trabalho incerto: um estudo comparativo Brasil, México e Itália. In: FRIGOTTO, Gaudêncio (Org.). Educação e crise do trabalho: perspectivas de final de século. São Paulo: Cortez, 1998.

Quando nós somos o outro. Questões teórico-metodológicas sobre os estudos comparados. Educação e Educação, v. XXI, n. 72, p. 197-230, ago. 2000a.

Cuando nosotros somos el outro. Cuestiones teórico-metodológicas sobre los estúdios comparados. In: LOPÉZ-VELAVERDE, Jaime C. (Coord.). Teoria y desarrollo de la investigación en educación comparada. México: Plaza y Valdés, 2000b.

CIAVATTA, Maria. A formação integrada: a escola e o trabalho como lugares de memória 
e de identidade. In: FRIGOTTO, Gaudêncio; CIAVATTA, Maria; RAMOS, Marise. Ensino médio integrado. Concepção e contradições. São Paulo: Cortez, 2005.

Estudos comparados sobre formação profissional e técnica. In: FRIGOTTO, Gaudêncio; CIAVATTA, Maria. A formação do cidadão produtivo. A cultura de mercado no ensino médio técnico. Brasília: Inep, 2006.

Historiografia em trabalho e educação. Como se constroem as categorias. Projeto de Pesquisa. Niterói: UFF, 2007. Mimeografado.

CUNHA, Luiz A. Ensino médio e ensino técnico na América Latina: Brasil, Argentina e Chile. Cadernos de Pesquisa, n. 111, p. 47-70, dez. 2000.

FONTANA, Josep. A história dos homens. Bauru: Edusc, 2004.

FONTES, Virgínia. História e verdade. In: FRIGOTTO, Gaudêncio; CIAVATTA, Maria (Orgs.). Teoria e educação no labirinto do capital. Petrópolis: Vozes, 2001.

GELPI, Ettore. Contraintes et creativités de l'educatión comparée et de l'histoire de l'educatión. In: CONGRÉS MONDIAL D'EDUCATIÓN COMPARÉE: EDUCATIÓN, CRISE ET CHANGERMENT, 6, 6-10 juillet 1987, Rio de Janeiro. Mimeografado.

HAYEK, Friedrich. O caminho da servidão. Rio de Janeiro: Instituto Liberal, 1987.

JAMESON, Fredric. Pós-modernismo. A lógica cultural do capitalismo tardio. São Paulo: Ática, 1996.

JAPIASSU, Hilton. Introdução ao pensamento epistemológico. 2. ed. Rio de Janeiro: Francisco Alves, 1977.

KONDER, Leandro. A derrota da dialética. Rio de Janeiro: Campus, 1988.

Limites e possibilidades de Marx e sua dialética para a leitura crítica da história neste início de século. In: FRIGOTTO, Gaudêncio e CIAVATTA, Maria. Teoria e educação no labirinto do capital. Petrópolis: Vozes, 2001, p. 98-114.

As artes da palavra. Elementos para uma poética marxista. São Paulo: Boitempo, 2005.

LE THÁNH KOI. L'educazione comparata. Torino: Loerscher, 1983.

LOPEZ-VALVERDE, Jaime Calderón (Coord.). Teoria y desarrollo de la investigación en educación comparada. México: Plaza y Valdés, 2000.

LOURENZO FILHO, Manoel B. Educação comparada. São Paulo: Melhoramentos, 1961.

MALERBA, Jurandir. Teoria e história da historiografia. In: A história escrita: teoria e história da historiografia. São Paulo: Contexto, 2006.

MARINI, Rui Mauro. Dialética da dependência. Petrópolis: Vozes/Clacso, 2000.

MARX, Karl; ENGELS, Friedrich. F. A ideologia alemã (Feuerbach). São Paulo: Ciências Humanas, 1979.

MARX, Karl. O método da economia política. In: _. Contribuição para a crítica da economia política. Lisboa: Estampa, 1977.

NÓVOA, Antonio. Histoire \& comparaision (Essais sur l'education). Lisbonne: Educa, 1998.

LUKÁCS, G. A arte como autoconsciência do desenvolvimento da humanidade. In: PAULO NETTO, José (Org.). Lukács. 2. ed. São Paulo: Ática, 1992, p. 189-203.

PUIGGRÓS, Adriana. Três artigos sobre questões da educação socialista. In: CIAVATTA FRANCO, Maria (Org.). Estudos comparados em educação na América Latina. São Paulo, Livros do Tatu/Cortez, 1992.

PUIGGRÓs, Adriana. Elementos para el análisis sócio-histórico de la educación 
popular em América Latina. Documento I. Introducción, Proyecto APPEAL, s. l., s. d. Mimeografado.

ROSSI, Pietro. La storia comparada entre investigación histórica y concepciones generales de la historia. Mexico: El Colegio de México, 1994a.

Historia comparada y ciencias sociales: de Max Weber a las teorias de la modernización. México: El Colegio de México, 1994b.

SILVEIRA, Elizabete da. O surgimento da disciplina Educação Comparada no Instituto de Educação em 1932: a sutileza de seu projeto, 1992. Dissertação (Mestrado em Educação), Niterói: Universidade Federal Fluminense.
TODOROV, Tzvetan. La conquista de América. La cuestion del otro. México: Siglo Veintiuno, 1987.

VILAR, Pierre. Iniciação ao vocabulário da análise histórica. Porto: Edições João Sá da Costa, 1985.

Pensar la historia. México: Instituto Mora, 1992

WEINBERG, Pedro D. La formación en América Latina y el Caribe a finales del milenio. Boletim Técnico do Senac, v. 25, n. 2, p. 3-17, maio/ago. 1999. 